\title{
HOW DO PATIENTS WHO PARTICIPATE IN CANCER SUPPORT GROUPS DIFFER FROM THOSE WHO DO NOT?
}

\author{
G.E. GRANDE ${ }^{\mathrm{a} * *}$, L.B. MYERS ${ }^{\mathrm{b}}$ and S.R. SUTTON ${ }^{\mathrm{c}}$ \\ a School of Nursing, Midwifery \& Social Work, The University of Manchester, Coupland III, Oxford Road, \\ Manchester, M13 9PL, UK \\ ${ }^{\mathrm{b}}$ Unit of Health Psychology, Department of Psychiatry \& Behavioural Sciences, University College London, UK \\ ${ }^{\mathrm{c}}$ General Practice \& Primary Care Research Unit, Department of Public Health \& Primary Care, \\ University of Cambridge, $U K$
}

\begin{abstract}
SUMMARY
Research has shown that cancer patients in general benefit from support group participation. However, few patients attend such groups. This study investigated differences between participants of a community cancer support group and a random selection of non-participants from the Cancer Registry. Data were collected through mail survey, and included variables identified through past research and variables derived from Leventhal's self-regulatory model of illness representations and the theory of planned behaviour. Sixty-three support group participants and 44 comparison sample respondents were recruited. Support group participants were more likely to be female, without a partner, younger, and to have more education and formal support than non-participants. They held more favourable views of support groups, believed that significant others were favourable towards participation, and perceived less difficulty in joining a group. They furthermore used more active, adaptive coping strategies and felt more control over their cancer, but were more distressed and anxious. Non-participants reported more support from a special person. A multivariate logistic regression analysis showed only psychosocial variables to be independent predictors of participation. As psychological variables are amenable to change, increase of appropriate support group participation should be possible, for instance by addressing patients' beliefs about support groups. Copyright (C) 2005 John Wiley \& Sons, Ltd.
\end{abstract}

KEY WORDS: support groups; cancer; oncology; theory of planned behaviour; illness representations; coping

\section{INTRODUCTION}

There is considerable evidence that cancer patients can benefit from participation in support groups. Reviews of research into cancer self-help groups (Borne et al., 1986), non-directive, professionally led groups (Hogan et al., 2002), and directive group interventions (Fawzy et al., 1995; Meyer and Mark, 1995) show improvement among participants in quality of life, coping, affect and,

*Correspondence to: School of Nursing, Midwifery \& Social Work, The University of Manchester, Coupland III, Oxford Road, Manchester M13 9PL, UK.

E-mail: Gunn.grande@manchester.ac.uk possibly, survival, although recent research has not confirmed the latter finding (Edelman et al., 2000). Although not all patients may benefit from support groups (Helgeson et al., 1999, 2000), groups overall appear to improve patient quality of life across a number of different formats. Fellow patients may provide positive role models, shared understanding and information on coping not available from family, friends and health professionals (Dakof and Taylor, 1990).

However, very few cancer patients utilise support groups (Pascoe et al., 2000; Plass and Koch, 2001; Taylor et al., 1986). This raises concerns that many more patients could benefit than those currently participating. To clarify this issue we need to investigate why people do not attend. Lack 
of participation due to, for example, adequate support elsewhere or preferring to cope through disengagement does not imply need for change. However, lack of participation due to misperceptions about groups or lack of encouragement, indicates that beneficial support group participation could and should be increased. To illuminate this issue we investigate relationships between demographic, clinical and psychosocial variables and membership of a non-directive community support group.

There has been little systematic investigation into why people attend cancer support groups. A literature review undertaken for the present study uncovered eleven studies since 1980 that compared participants in non-directive cancer support groups with non-participants (Bauman et al., 1992; Eakin and Strycker, 2001; Edgar et al., 1996; Katz et al., 2002; Krizek et al., 1999; McGovern et al., 2002; Michalec et al., 2004; Poole et al., 2001; Stevens and Duttlinger, 1998; Taylor et al., 1986; Winefield et al., 2003).

The review found that cancer group participants were predominantly of a higher socio-economic status, female and younger compared to nonparticipants. They were also more likely to use other professional and voluntary support. However, participants were both found to have poorer social support and better social support than those who did not attend groups. Contradictory findings on social support may reflect a lack of consistency in measures used in the support group literature (Hogan et al., 2002), which makes comparison between studies difficult. The review found little information on why patients may join groups. Group participants scored higher on low helplessness/high fighting spirit and desired more information than non-participants. However, participants were also more worried about their cancer and generally had more emotional problems, although one study found the reverse for anxiety and stress.

The reviewed studies present problems in terms of their generalisability, design and lack of a theoretical framework. None of the studies were conducted in the UK. Eight out of the eleven studies considered patients of a single diagnosis and/or gender only and patients were predominantly recruited from oncology/specialist settings, thus samples may be unrepresentative of the cancer population as a whole. In many cases group participants and non-participants were recruited from different settings, therefore some group differences may be due to differences in the settings, rather than support group participation per se. Consequently, there is need for a UK study in which both cancer support group participants and non-participants are recruited from a community setting, which incorporates men and women and a representative range of cancers. The present study addresses these issues.

Most studies on why people join support groups have furthermore been atheoretical and there is a need to integrate the available empirical evidence and establish a proper theory base to guide research development. If a potential aim is to increase support group use, theories that incorporate psychological variables amenable to change are particularly relevant.

To help explain why people may use support groups as part of dealing with cancer the current study draws on two major health psychology theories: Leventhal's self-regulatory model of illness representations (Leventhal et al., 1997) and the theory of planned behaviour (TPB) (Ajzen, 1988, 2002). Serious illness requires considerable adjustment, and theories of illness and coping propose several coping strategies that patient may employ to address this adjustment (Moos and Shaefer, 1986; Taylor, 1983). Which strategies are adopted largely depends on patients' appraisal of the illness (Moos and Shaefer, 1986; Leventhal et al., 1997).

Coping associated with patients' cognitive appraisal of illness has been extensively researched within Leventhal's model. Perceptions of cure/ controllability of the illness have been found to be positively associated with problem focused coping, cognitive reappraisal and support seeking. In contrast, cognitive representations of the illness as long term and with serious consequences are correlated with coping involving avoidance, denial and emotional expression (Hagger and Orbell, 2003). Leventhal et al. (1997) also propose that emotional illness representations are formed parallel to cognitive representations. However, their association with coping has been little researched. Fear and anxiety appear, for example, to encourage support seeking, preventive behaviours and medical care seeking, but this relationship is not always clear (e.g. Cameron et al., 1993; Leventhal et al., 2001).

As support group participation implies an active, open approach to cancer that reaches beyond one's immediate network, the coping strategies most likely to correlate with participation 
should involve problem focused coping and support seeking, and possibly, cognitive reappraisal. These have been termed 'adaptive' forms of coping (Carver et al., 1989) and appear compatible with the fighting spirit/low helplessness associated with support group use in past research. Conversely, 'maladaptive' strategies such as denial, disengagement and emotional venting (Carver et al., 1989) seem less likely to lead to group participation. Drawing on Leventhal's model, we therefore propose that support group participants should perceive their cancer to be more controllable, possibly respond to it with more anxiety, and display more adaptive coping in relation to their illness than non-participants.

Whether adaptive coping strategies take the form of support group participation is likely to depend on people's beliefs about such groups. The TPB (Ajzen, 1988, 2002) postulates that the intention to perform a behaviour depends on the attitude towards the behaviour, the influence of others (subjective norm) and perceived behavioural control. Actual behaviour depends on intention and behavioural control. Meta-analyses of observational studies show that the TPB accounts for between 35 and $50 \%$ of the variance in intention and between 26 and $35 \%$ of the variance in behaviour, across a range of health- and nonhealth-related behaviours (Sutton, 2004). Attitudes in part depend on people's beliefs about the benefits of a behaviour, and subjective norm in part on beliefs about important others' attitudes towards it. Drawing on the TPB, we therefore propose that support group participation is more likely if people believe that participation will be beneficial, that others think they should participate and that it is easy to join a group.

Finally, whether people seek support from family and friends or go elsewhere may depend on how well they feel supported within their social network. Our literature review suggested that the relationship between social support and support group use was not clear, possibly due to a lack of consistency in measures. Perceived support, rather than social network per se, appears to be protective during stressful events (Cohen and Wills, 1985). Therefore, we propose that perceived support is most likely to influence support seeking during the stress of cancer illness.

In light of past research our study hypotheses were that community support group participants would be more likely to be female, of higher socioeconomic status, lower age and to utilise more statutory and voluntary support than other cancer patients. In accord with Leventhal's model, group participants should perceive their cancer as more controllable, possibly respond to it with more anxiety, and use more problem focused coping, support seeking and cognitive reappraisal in coping with it. In accord with TPB, community support group participants should have more positive beliefs about support groups, perceive others to have more positive views of groups and consider it easier to join a group. Finally, their perceived social support should be lower compared to other cancer patients.

\section{METHOD}

The study was cross-sectional comparing participants in a community cancer support group with a random sample of cancer patients from the Cancer Registry. Data were collected through self-completed, postal survey and Cancer Registry records.

\section{Participants}

Support group participants were recruited through the Cambridge Cancer Help Centre (CCHC). This is a community support group for those with cancer of all diagnoses. The Centre is regularly open twice a week and is used at other times for related activities. It is run by a lay centre coordinator and volunteers, the majority of whom have had cancer. Whilst complementary therapies are available, this is essentially a peer support group. All $103 \mathrm{CCHC}$ members with a cancer diagnosis were approached for the study. Members pay a small membership fee to be on the $\mathrm{CCHC}$ Newsletter mailing list and encompass the vast majority of patients who have visited the centre.

For the comparison sample the East Anglian Cancer Intelligence Unit (CIU) randomly selected 200 people from Cancer Registry records. Inclusion criteria were age 18 or above, malignant cancer, diagnosis between 1990 and 2002 inclusive, no recorded date of death, and residence within the catchment area of the CCHC. Identified $\mathrm{CCHC}$ members and people without a recorded GP were excluded.

Power calculations showed that a study sample of 100 would give 0.80 power to detect a sex difference in support group participation of a 
moderate effect size $(0.28)$ (e.g. $70 \%$ females in support group versus $50 \%$ in the comparison group), and similar power to detect a mean difference in continuous variable scales of moderate effect size (0.57) at $\alpha=0.05$ for two-tailed tests, i.e. a difference of 0.57 standard deviations for a measure.

\section{Procedure}

CCHC members were notified of the study through the $\mathrm{CCHC}$ newsletter. The centre coordinator next mailed pre-prepared survey packs to members with cancer. The CIU sent a similar survey pack to comparison sample patients via their GP who would forward the survey if appropriate. This ensured that surveys were not sent to patients who had died or did not acknowledge their cancer diagnosis. Non-forwarded surveys were returned to the CIU. All respondents sent completed questionnaires and consent form to the researcher. Permission to identify respondents' records on the Cancer Registry was sought from both samples.

The CIU provided anonymous Cancer Registry information for all 200 randomly selected comparison sample patients. An identity number enabled the CIU to identify records of survey respondents with their permission, and to distinguish data of patients whose GP returned the survey from the remainder. Study procedures and materials were approved by the Local Research Ethics Committee.

\section{Measures}

Age, sex, education, age, marital and employment status were collected through the survey. The CIU provided diagnosis, date of diagnosis and socio-economic status of residential ward (Index of Multiple Deprivation, IMD) (Indices of Deprivation, 2000).

\section{Health status}

Health status was measured through the Functional Status and General Health subscales of the European Organisation for Research and Treatment into Cancer (EORTC) QLQ-C30 (Aaronson et al., 1993, Fayers et al., 2001). Functional status consists of five items, e.g. 'Do you need to stay in bed or a chair during the day?' with a 4-point response scale: 1: Not at all-4: Very much. General health consists of two items, e.g. 'How would you rate your overall health during the past week?' with a 7-point response scale: 1: Very poor7: Excellent.

\section{Illness perceptions}

The Revised Illness Perception Questionnaire (IPQ-R) measures cognitive and emotional appraisal of illness based on Leventhal's self-regulatory model of illness perceptions (Moss-Morris et al., 2002). Two subscales were used for the study, Perceived Personal Control over Illness and Emotional Response to Illness, each comprising six items. Examples are: 'There is a lot I can do to control my cancer' (personal control); 'When I think about my cancer I get upset' (emotional response). Responses are made on 5-point scales: 1: Strongly disagree-5: Strongly agree.

\section{Coping strategies}

The Brief COPE inventory aims to measure the main coping strategies adopted towards a stressor (Carver, 1997). Six of its subscales were used to measure adaptive coping in relation to cancer: active coping, planning, positive reframing, acceptance, using emotional support and using instrumental support. Each subscale consists of two items. Examples include: 'I've been trying to make the situation better' (active coping); 'I've been trying to come up with a strategy about what to do' (planning); 'I've been looking for something good in what's happening' (reframing); 'I've been learning to live with it' (acceptance); 'I've been getting emotional support from others' (emotional support); 'I've been getting help and advice from other people' (instrumental support). Responses are made on 4-point scales: 1: I haven't been doing this at all-4: I've been doing this a lot.

\section{Anxiety and depression}

The hospital anxiety and depression scale (HADS) (Zigmond and Snaith, 1983) measures anxiety and depression during the last week, using seven items for each. Examples include 'Worrying thoughts go through my mind' (anxiety) and 'I feel 
as if I am slowed down' (depression). Responses are made on 4-point scales, e.g. 0: only occasionally-3: a great deal of the time.

\section{Social and formal support}

The multidimensional scale of perceived social support (MSPSS) (Zimet et al., 1988) measures perceived support from a special person, from family and from friends, using four items for each. Examples are: 'There is a special person who is around when I am in need' (special person); 'I can count on my friends when things go wrong' (friends); 'I get the emotional help and support I need from my family' (family). Responses are made on 7-point scales: 1: Very strongly disagree7: Very strongly agree. Respondents were furthermore asked to tick use of any of the following statutory and voluntary services available locally: general practitioner, district nurse, Macmillan cancer specialist nurse advice, Marie Curie cancer nurse care, physiotherapist, occupational therapist, social worker, day centre, counselling, complementary therapy, oncologist, hospital cancer support group, Cambridge Cancer Help Centre, web support group, BACUP telephone information service, church or other. The comparison group was in addition asked if they had ever participated in a cancer support group to capture any support group use beyond the locally available groups.

\section{Theory of planned behaviour variables}

Items were constructed to measure beliefs about outcomes of support group participation (attitude), beliefs about others' views about such participation (social norm) and perceived difficulty of joining a support group (perceived behavioural control), in accord with standard TPB question formats recommended by Ajzen (2002).

Beliefs about positive and negative outcomes of support group participation were measured through seven items constructed from the available literature on views of support groups (Adamsen, 2002; Dakof and Taylor, 1990; Gray et al., 1997a, b; Pilisuk et al., 1997; Stevenson and Coles, 1993; Thiel de Bocanegra, 1992). Examples of items include: 'Joining a cancer support group would give me useful information and advice about cancer'; 'Joining a cancer support group would make me depressed'. Responses were made on a 7-point scale: 1: Strongly disagree-7: Strongly agree.

Other people's views of participation were measured through two items measuring the perceived views of 'most people who are important to me' and 'my doctors'. The response was made on a 7-point scale from 1: Definitely should not to 7: Definitely should. For example, 'My doctors think that 1: I definitely should not/7: I definitely should join a cancer support group'.

Perceived difficulty of joining a group was measured by one item: 'It would be difficult for me to join a cancer support group, even if I wanted to'. Response were made on a 7-point scale ranging from '1: Strongly disagree' to '7: Strongly agree'.

TPB items for CCHC members were phrased according to actual experience (e.g. 'Participating in a cancer support group makes me depressed'), whilst items for comparison group respondents were stated as an imagined situation (e.g. 'Joining a cancer support group would make me depressed').

\section{Statistical analysis}

Representativeness of comparison sample respondents relative to the Cancer Registry sampling frame was assessed using Pearson's $\chi^{2}$ for categorical variables, and One-way ANOVA or KruskalWallis One-way ANOVA, as appropriate, for continuous variables (Siegel and Castellan, 1988). Analysis of differences between support group participants and non-participants were first performed using univariate logistic regression analysis, as recommended for variables considered for subsequent multivariate logistic regression (Hosmer and Lemeshow, 2000). Variables that differed between groups at $p<0.25$ in the univariate analysis were entered into a multivariate forward stepwise logistic regression analysis, as non-significant variables may contribute to models in unforeseen ways due to complex interrelationships (Hosmer and Lemeshow, 2000). TPB variables and Brief COPE scales were first subjected to Principal Components Analysis and reliability testing (Cronbach's $\alpha$ ) to assess whether their items should be combined for the multivariate analysis. Relationships between length of support group membership and psychosocial variables were investigated using Spearman's correlation coefficient due to considerable skew in these variables. Analysis was performed using SPSS 10.1 for Windows. 


\section{RESULTS}

\section{Study samples}

Sixty three $(61 \%)$ of 103 CCHC participants completed the survey and 58 consented to having their Cancer Registry records identified. For the comparison sample GPs returned $44(22 \%)$ of 200 envelopes to the CIU. Thus, a maximum of 156 $(78 \%)$ envelopes were forwarded to patients. Reasons for returning envelopes were that the patient or GP was no longer with the practice (20 and 4 , respectively), the patient had died or was unsuitable for research (4), and in 16 cases no reason was given. Forty four $(28 \%)$ of the comparison sample completed the survey and 39 consented to having their Cancer Registry records identified.

These samples provide reasonable statistical power. Post hoc power calculations show that sample sizes of 63 and 44 yield a power of 0.71 to detect a difference in group means of moderate effect size $(0.50)$ at $\alpha=0.05$ for twotailed tests, while a total sample of 107 gives a power of 0.87 to detect a sex difference in support group participation of moderate effect size $(0.30)$ at $\alpha=0.05$.

For the comparison sample there were no significant differences between respondents, nonrespondents and patients whose GP returned the survey for time since diagnosis, cancer diagnosis, number of cancer diagnoses, gender, age or IMD code. Comparison sample respondents were therefore representative of the sampling frame in terms of the key clinical and demographic variables. Data were not available for non-respondents of the CCHC sample to enable a similar analysis for support group members.

Four comparison sample respondents had used a professionally led hospital support group, but no other support group use was reported. It was decided to retain these within the comparison sample, as the hospital groups were different in structure from the CCHC. Eight of the CCHC sample had used hospital support groups.

\section{Univariate analysis}

$\mathrm{CCHC}$ members were significantly more likely to be female than the comparison group (Table 1).
They were also younger and had finished their education at a higher age. An odds ratio $(\mathrm{OR})<1$ shows a negative relationship between the variable and support group membership, OR $>1$ a positive relationship. In this and subsequent results the median and interquartile range are reported for continuous variables, as all except age were considerably skewed.

CCHC members were significantly more likely to have breast cancer than the comparison group (Table 2), which may relate to the different sex composition of the two groups. The groups were otherwise similar regarding clinical variables and health status.

CCHC members had more positive beliefs about support groups than the comparison sample (Table 3). They were more likely to believe that support groups provided useful information and advice, positive role models, special understanding and support, and less likely to believe that they were depressing places where one would be burdened with other people's cancer problems. They also believed that important others and doctors were more positive towards their group participation and felt there was less difficulty in joining a group. However, only 62 of 107 respondents responded to the item measuring doctors' views (many making comments such as 'no idea', 'never discussed it with him'), making this the variable with the highest number of missing values.

CCHC respondents were more likely to use adaptive coping strategies than the comparison group (Table 4), that is, active coping, planning, reframing, acceptance and emotional and instrumental support seeking. They furthermore felt greater personal control over their cancer, but were also more distressed over it and more anxious generally. Finally, the CCHC sample reported less support from a special person than the comparison sample, although support from family and friends was similar. Finally, the CCHC group had used more types of other formal support than the comparison group.

\section{Combining items for multivariate analysis}

Items within the Brief COPE and the TPB measures were combined for the multivariate logistic regression analysis. Within these measures items are likely to be considerably intercorrelated 
Table 1. Demographic variables: differences between support group participants and non-participants (OR $>1$ denotes an increased likelihood of group participation)

\begin{tabular}{|c|c|c|c|c|}
\hline & $\mathrm{CCHC}$ group & Comparison group & OR $(95 \% \mathrm{CI})$ & $p$-Value \\
\hline & $N(\%)$ & $N(\%)$ & & \\
\hline \multicolumn{5}{|l|}{ Sex } \\
\hline Female & $52(83.9 \%)$ & $27(61.4 \%)$ & $3.27(1.31,8.12)$ & \multirow[t]{2}{*}{$p=0.011$} \\
\hline Male & $10(16.1 \%)$ & $17(38.6 \%)$ & 1 & \\
\hline \multicolumn{5}{|l|}{ Married/cohabiting } \\
\hline Yes & $35(56.5 \%)$ & $33(75.0 \%)$ & $0.43(0.18,1.01)$ & \multirow[t]{2}{*}{$p=0.052$} \\
\hline No & $27(43.5 \%)$ & $11(25.0 \%)$ & 1 & \\
\hline \multicolumn{5}{|l|}{ Employment } \\
\hline Full time & $11(17.7 \%)$ & $8(18.2 \%)$ & $1.41(0.61,3.22)^{\mathrm{a}}$ & \multirow[t]{4}{*}{$p=0.41$} \\
\hline Part time & $4(6.5 \%)$ & $1(2.3 \%)$ & & \\
\hline Unemployed & $12(19.4 \%)$ & $5(11.4 \%)$ & 1 & \\
\hline Retired & $35(56.5 \%)$ & $30(68.2 \%)$ & & \\
\hline \multicolumn{5}{|l|}{ IMD 2000 quintile for ward of residence } \\
\hline 1 Highest SES & $17(41.5 \%)$ & $22(59.5 \%)$ & $0.47(0.16,1.41)^{\mathrm{b}}$ & \multirow[t]{5}{*}{$p=0.17$} \\
\hline 2 & $12(29.3 \%)$ & $9(24.3 \%)$ & & \\
\hline 3 & $1(2.4 \%)$ & $2(5.4 \%)$ & 1 & \\
\hline 4 & $10(24.4 \%)$ & $2(5.4 \%)$ & & \\
\hline \multirow[t]{2}{*}{5 Lowest SES } & $1(2.4 \%)$ & $2(5.4 \%)$ & & \\
\hline & Median (IQR) & Median (IQR) & & \\
\hline Age $(n=63 / 44)$ & $61.0(15.3)$ & $64.5(18.8)$ & $0.95(0.91,0.99)$ & $p=0.005$ \\
\hline Age when finished education $(n=60 / 42)$ & $17.5(5.0)$ & $16.0(3.5)$ & $1.14(1.01,1.29)$ & $p=0.029$ \\
\hline
\end{tabular}

${ }^{a}$ Employed with not employed as reference category.

${ }^{\mathrm{b}} \mathrm{SES}$ categories 1-2 with categories 3-5 as reference category.

(Carver, 1997). Highly intercorrelated items should not be entered into a multivariate logistic regression together (Norusis, 1994). To guide this process Principal Component Analyses with Oblimin rotation were performed on each measure (with Eigenvalue $>1$ as factor cut-off point), followed by reliability testing.

For the TPB measure (see Table 2) the six items for respondents' own beliefs about support groups all loaded on a first factor and showed good internal reliability (Cronbach's $\alpha=0.896$ ) and were combined into one scale. Items were summed after reversing the negative scales. The remaining TPB items all loaded on a second factor, although the two items about views of others had a secondary loading on Factor 1 as well. However, it was decided to keep items relating to views of others, difficulty of joining a group and beliefs about support groups separate from each other, as these are conceptually different. The high number of missing responses for the item on doctors' views of participation meant that its inclusion in the multivariate analysis resulted in an unacceptably unstable model. In the final analysis only the item measuring important others' views of participation was therefore retained to measure views of others.

Analysis of Brief COPE scales yielded three factors. Active coping, planning and reframing items loaded on the first factor. The emotional and instrumental support seeking items loaded on Factor 2, and acceptance items loaded on Factor 3. These findings are similar to Carver's (1997) factor analysis, except that acceptance emerges more clearly as a separate concept in our analysis. Items within factors showed good internal reliability (Factor 1: $\alpha=0.914$; Factor 2: $\alpha=0.851$; Factor 3: $\alpha=0.850$ ). Thus, active coping, planning and reframing items were combined into one scale (termed 'Active approach to coping'), whilst support seeking and acceptance items formed a further two. 
Table 2. Clinical variables and self reported health: differences between support group participants and non-participants

\begin{tabular}{|c|c|c|c|c|}
\hline & $\mathrm{CCHC}$ group & Comparison group & OR $(95 \% \mathrm{CI})$ & $p$-Value \\
\hline & $N(\%)$ & $N(\%)$ & & \\
\hline \multicolumn{5}{|l|}{ Cancer diagnosis } \\
\hline Breast & $29(63.0 \%)$ & $15(38.5 \%)$ & $2.73(1.12,6.58)^{\mathrm{a}}$ & \multirow[t]{8}{*}{$p=0.025$} \\
\hline Female genital & $3(6.5 \%)$ & $3(7.7 \%)$ & 1 & \\
\hline Male genital & $1(2.2 \%)$ & $8(20.5 \%)$ & & \\
\hline Colorectal & $2(4.3 \%)$ & $5(12.8 \%)$ & & \\
\hline Haematological & $5(10.9 \%)$ & $3(7.7 \%)$ & & \\
\hline Melanomas & $1(2.2 \%)$ & $1(2.6 \%)$ & & \\
\hline Lung & $0(0 \%)$ & $1(2.6 \%)$ & & \\
\hline Other & $5(10.9 \%)$ & $3(7.7 \%)$ & & \\
\hline \multicolumn{5}{|c|}{ Number of cancer diagnoses } \\
\hline One & $38(82.6 \%)$ & $35(89.7 \%)$ & $0.54(0.15,1.96)$ & \multirow[t]{2}{*}{$p=0.352$} \\
\hline \multirow[t]{2}{*}{ More than one } & $8(17.4 \%)$ & $4(10.3 \%)$ & 1 & \\
\hline & Median (IQR) & Median (IQR) & & \\
\hline \multicolumn{5}{|l|}{ Years since diagnosis } \\
\hline$(n=62 / 44)$ & $8.0(7.3)$ & $6.5(4.8)$ & $1.02(0.96,1.10)$ & $p=0.409$ \\
\hline \multicolumn{5}{|l|}{ EORTC scores } \\
\hline $\begin{array}{l}\text { Functional status } \\
(n=62 / 44)\end{array}$ & $86.7(26.7)$ & $86.7(26.7)$ & $1.01(0.98,1.02)$ & $p=0.571$ \\
\hline $\begin{array}{l}\text { Global health } \\
(n=61 / 44)\end{array}$ & $83.3(41.7)$ & $83.3(25.0)$ & $1.00(0.99,1.02)$ & $p=0.760$ \\
\hline
\end{tabular}

${ }^{a}$ Breast cancer with all other cancer diagnoses as reference category.

Table 3. Beliefs about support group participation: differences between support group participants and non-participants (high scale scores denote strong agreement with statements)

\begin{tabular}{|c|c|c|c|c|}
\hline & $\begin{array}{l}\text { CCHC } \\
\text { group }\end{array}$ & $\begin{array}{l}\text { Comparison } \\
\text { group }\end{array}$ & OR $(95 \% \mathrm{CI})$ & $p$-Value \\
\hline Beliefs about outcomes of support group participation & Median (IQR) & Median (IQR) & & \\
\hline Useful information and advice about cancer $(n=61 / 39)$ & $6.0(2.0)$ & $4.0(1.0)$ & $1.82(1.33,2.48)$ & $p<0.001$ \\
\hline Positive role models to help one cope $(n=61 / 39)$ & $7.0(1.0)$ & $4.0(1.0)$ & $2.03(1.48,2.76)$ & $p<0.001$ \\
\hline Understanding from others with similar experience $(n=60 / 39)$ & $7.0(1.0)$ & $4.0(1.0)$ & $2.63(1.79,3.87)$ & $p<0.001$ \\
\hline Place of positive, mutual support outside the home $(n=59 / 40)$ & $7.0(1.0)$ & $4.0(1.8)$ & $2.66(1.85,3.83)$ & $p<0.001$ \\
\hline Would make one depressed $(n=60 / 40)$ & $1.0(1.0)$ & $4.5(3.8)$ & $0.53(0.41,0.69)$ & $p<0.001$ \\
\hline Burdened with other people's cancer problems $(n=58 / 40)$ & $2.0(2.3)$ & $4.5(2.0)$ & $0.50(0.37,0.66)$ & $p<0.001$ \\
\hline \multicolumn{5}{|c|}{ Beliefs about others' views of respondents' support group participation } \\
\hline Positive views from important others $(n=58 / 36)$ & $6.0(3.0)$ & $4.0(0.8)$ & $2.48(1.68,3.65)$ & $p<0.001$ \\
\hline Positive views from doctors $(n=39 / 23)$ & $5.0(3.0)$ & $4.0(0.0)$ & $2.02(1.20,3.42)$ & $p=0.008$ \\
\hline \multicolumn{5}{|l|}{ Perceived behavioural control } \\
\hline Difficulty of joining group (58/34) & $2.0(3.0)$ & $4.0(3.5)$ & $0.78(0.62,0.97)$ & $p=0.026$ \\
\hline
\end{tabular}

\section{Multivariate logistic regression}

A first analysis performed only with demographic and clinical variables showed that only sex and age were significantly associated with support group participation. The remaining clinical and demographic variables made no further contribution to the model. Diagnosis and socio-economic 
Table 4. Psychosocial variables: differences between support group participants and non-participants

\begin{tabular}{|c|c|c|c|c|}
\hline & $\mathrm{CCHC}$ group & Comparison group & OR $(95 \% \mathrm{CI})$ & $p$-value \\
\hline Tendency to use coping strategy (Brief COPE) & Median (IQR) & Median (IQR) & & \\
\hline Active coping $(n=60 / 41)$ & $8.0(2.0)$ & $6.0(3.0)$ & $1.68(1.31,2.16)$ & $p<0.001$ \\
\hline Planning $(n=61 / 41)$ & $8.0(2.0)$ & $5.0(6.0)$ & $1.46(1.19,1.79)$ & $p<0.001$ \\
\hline Reframing $(n=61 / 40)$ & $7.0(3.0)$ & $5.0(4.0)$ & $1.58(0.26,1.98)$ & $p<0.00$ \\
\hline Acceptance $(n=63 / 41)$ & $8.0(1.0)$ & $7.0(2.0)$ & $1.31(1.003,1.71)$ & $p=0.048$ \\
\hline Emotional support seeking $(n=62 / 41)$ & $7.0(2.3)$ & $6.0(3.5)$ & $1.27(1.02,1.58)$ & $p=0.03$ \\
\hline Instrumental support seeking $(n=61 / 41)$ & $6.0(4.0)$ & $3.0(4.0)$ & $1.50(1.22,1.84)$ & $p<0.00$ \\
\hline \multicolumn{5}{|l|}{ Illness representations (IPQ-R) } \\
\hline $\begin{array}{l}\text { Perceived level of personal control over } \\
\text { cancer }(n=57 / 36)\end{array}$ & $23.0(7.0)$ & $18.0(4.8)$ & $1.22(1.10,1.36)$ & $p<0.00$ \\
\hline $\begin{array}{l}\text { Emotional response to cancer: level of } \\
\text { distress }(n=60 / 36)\end{array}$ & $18.0(8.5)$ & $16.0(6.8)$ & $1.12(1.03,1.22)$ & $p=0.010$ \\
\hline \multicolumn{5}{|l|}{ Level of negative affect (HADS) } \\
\hline Depression $(n=62 / 43)$ & $3.0(4.0)$ & $3.0(4.0)$ & $1.06(0.94,1.20)$ & $p=0.361$ \\
\hline Anxiety $(n=61 / 43)$ & $7.0(5.0)$ & $3.0(6.0)$ & $1.20(1.07,1.34)$ & $p=0.002$ \\
\hline \multicolumn{5}{|l|}{ Level of perceived social support (MSPSS) } \\
\hline From special person $(n=61 / 40)$ & $24.0(11.5)$ & $28.0(4.8)$ & $0.92(0.86,0.99)$ & $p=0.027$ \\
\hline From family $(n=60 / 39)$ & $24.0(9.5)$ & $26.0(10.0)$ & $0.98(0.91,1.04)$ & $p=0.456$ \\
\hline From friends $(n=58 / 40)$ & $22.0(8.3)$ & $24.0(10.5)$ & $0.99(0.93,1.06)$ & $p=0.842$ \\
\hline Types of other formal support used & $5(3)$ & $2(1)$ & $2.00(1.48,2.67)$ & $p<0.001$ \\
\hline
\end{tabular}

area of residence, which both had a high number of missing values, could therefore be omitted, and only age and sex were retained for subsequent analysis.

The following psychological variables were entered into analysis alongside age and sex: TPB beliefs about support groups, important others' views of group participation, and difficulty of joining support groups; Brief COPE 'active approach to coping', support seeking and acceptance; IPQ-R personal control and emotional response to cancer; HADS anxiety; MSPSS perceived support from a special person. Number of services used was also entered. Table 5 shows the resulting model. This model classified $92.5 \%$ of cases correctly.

Positive beliefs about support groups, important others' positive beliefs about participation and an active approach to coping were positively associated with support group membership. Perceived support from a special person, however, was negatively associated with group participation. Demographic variables made no significant contribution to the model once psychological variables were controlled for. Neither did perceived control over cancer, emotional response, support seeking, anxiety or perceived difficulty of joining a group.

Length of support group membership and psychosocial variables

Support group respondents had been members of the CCHC a median of 5 years (IQR 7 years). No significant relationships were found between psychosocial variables and length of support group membership. In fact, the valence of the correlation coefficient suggests that length of membership was associated with increasingly negative beliefs about support groups, less perceived control over illness and less active coping.

\section{SUMMARY AND DISCUSSION}

In accord with study hypotheses, support group members were more likely to be female, younger, more educated, and utilised formal support more than the comparison group. In accord with the theory of planned behaviour (TPB), group mem- 
Table 5. Variables associated with support group membership: multivariate logistic regression model for sex, age, psychological variables and number of services $(n=80)$

\begin{tabular}{lcc}
\hline & OR (95\% CI) & $p$-value \\
\hline Positive beliefs about support groups & $1.20(1.06,1.36)$ & 0.005 \\
Positive views of important others' towards participation & $2.23(1.20,4.13)$ & 0.011 \\
Active approach to coping & $1.30(1.05,1.61)$ & 0.016 \\
Support from special other & $0.77(0.65,0.91)$ & 0.002 \\
Constant & & 0.008 \\
\hline
\end{tabular}

Model $\chi^{2}=58.25, \mathrm{df}=4, p<0.0001$. Residual $\chi^{2}$ of variables not in equation $=9.358, \mathrm{df}=9, p=0.424$; goodness of fit of 88.43 .

bers held more positive beliefs about the benefits of support group participation, felt others were more supportive of participation and perceived less difficulty in joining a group. They felt greater personal control over their cancer, used more adaptive coping, but also felt more distress over their cancer and general anxiety, as implied by Leventhal's self-regulatory model of illness representations. Finally, support group members received less support from 'a special person' than the comparison group.

Multivariate analysis showed that the significant, independent predictors of group participation were beliefs about the benefits of support groups, perceived support from important others regarding participation, an active approach to coping (i.e. active coping, planning, reframing), and lack of support from a special person.

\section{Implications of the study}

The study indicates that psychosocial variables may be the important determinants of support group membership, rather than demographic or clinical characteristics. This implies that support group use could be increased by targeting psychological variables. Interventions have been effective in changing both coping strategies (De Ridder and Schreurs, 2001) and attitudes (Hardeman et al., 2002). However, we need to consider how and under what circumstances it would be appropriate to seek to change psychological variables to influence support group participation. Variables relating to the TPB, i.e. beliefs about support groups and others' views of support groups, appear most relevant here.
If cancer patients do not use support groups because they hold negative perceptions about groups that appear incorrect to group organisers or members, this implies that attempts at change are justified to enable patients to make more informed choices about joining groups. Here relatively low cost interventions may make a broad impact. If typical misperceptions about support groups can be identified, targeted information to address perceptions may prove effective, in particular during early stages of illness while patients are still trying to establish what support options are available. However, this would require better understanding both of patients' perceptions of groups and what different types of groups offer patients.

If cancer patients do not use support groups because of a lack of encouragement from others, interventions through health professionals may be appropriate, as they are likely represent important others whose opinions are valued. In the present study doctors' opinion of support group participation was often not known, as it had reportedly not been expressed, and this variable had to be omitted from the final, multivariate analysis. However, where doctors' views were known, they were significantly related to group participation. Communication between health professionals and groups and endorsement of appropriate groups by professionals, may therefore have considerable impact on participation. Views of next of kin may be more important, but less amenable to intervention, and exploration of the impact of health professional endorsement may prove more fruitful.

None of the above interventions are likely to affect support group use if people do not perceive the purported benefits of groups to be of personal 
importance to them, again in accord with the TPB (Ajzen, 1988). Purported benefits may be irrelevant if patients are already adequately supported or feel little psychological distress over their illness. Group participation furthermore probably represents an acceptable approach only to patients whose coping involves facing their cancer, rather than denial or disengagement. Therefore, support groups are not suitable for all. For example, Helgeson et al. (2000) found that peer discussion groups may mainly benefit women who lack support and in fact be harmful for women who already are well supported. It would therefore be misguided to seek to increase support groups for all patients in all circumstances. However, targeted information and professional endorsement is likely to facilitate support group uptake for those who are ready to take up this option, rather than exert undue pressure to participate in groups. Any planned intervention would clearly need to work with local support groups to ensure there is sufficient capacity to absorb an increase in uptake.

\section{Limitations of the study}

The main limitations of the study are its crosssectional design and the limited assessment of TPB variables. The cross-sectional design means that we cannot be certain of the causal direction between study variables and support group participation. Although it is likely that positive beliefs about support groups make participation more likely, beliefs about support groups may also become more positive as a result of group participation. However, our analysis suggested there was no relationship between length of CCHC membership and psychosocial variables, which indicates that, e.g. beliefs are not affected by prolonged exposure to a group. Length of participation was calculated from date of joining, the date itself likely to be unaffected by the psychosocial variables investigated. Nevertheless, this does not rule out that a single exposure to support groups may effect changes or that frequency of attendance rather than length itself may be important. The cross-sectional design furthermore required $\mathrm{CCHC}$ members to assess an experienced situation while comparison group respondents considered a hypothetical situation when assessing benefits of group participation, and it is not clear how easily the two can be compared.
Prospective research is required to address these issues.

In terms of TPB variables, we did not assess outcome evaluations or motivations to comply with the views of others, in part to reduce respondent workload. Furthermore, perceived benefits and views of others should only influence participation indirectly by affecting intention to participate. However, in this cross-sectional design it was unfeasible to ask support group users about their intention to participate in a group. Finally, we did not fully explore the many hurdles that may prevent people from translating an intention into action. We used a single, undifferentiated question about behavioural control, i.e. belief about the difficulty of joining a support group. This showed little predictive power, in contrast to a large body of research showing the importance of perceived behavioural control in predicting behaviour (Norman and Conner, 1996; Godin and Kok, 1996). In reality patients are likely to face several hurdles in joining support groups, both practical (health and mobility, transport, family and work commitments) and psychological (lack of confidence in walking into a room of strangers), all of which would limit patients' ability to attend a group, but many of which could be addressed. Future research should therefore explore potential internal and external barriers to participation to improve predictive power and identify appropriate variables for change.

\section{Directions for future research}

Despite the above limitations, the study progresses research within this field by considering support group participation within a well-tested theoretical framework and identifying variables warranting future investigation within this framework.

To build on this work prospective studies are required to test whether identified factors truly are precursors of utilisation of support groups and to improve our understanding of contributing variables. Ideally, patients' perceptions about support groups and other cancer support should be charted from first diagnosis, alongside adopted coping strategies, perceptions of illness, informal support and perceptions of need. We need to understand when, how and for whom support groups fit into the cancer journey and which factors impact on this. Here research on coping suggests that within- 
person process measurement is more fruitful in predicting associations than across-person assessment (Tennen et al., 2000), and this is likely to apply to other variables as well.

Support groups have a variety of formats. Alongside the improvements to TPB variable measurement mentioned in the previous section, we also need a better understanding of what different types of support groups mean to patients and refine TPB measures to reflect this. By measuring beliefs in relation to specific rather than generic examples of support groups, we should be able to improve these measures' ability to predict actual group participation (Ajzen, 2002). Nevertheless, support groups all have a common denominator of meeting other people with cancer, which may be a main factor influencing patients' perceptions of groups and decisions to join. There is some indication that once patients join one support group, they often subsequently become members of more than one type (Michalec et al., 2004). Therefore, the precise format may be less important than the general peer support context.

Finally, proposed extensions to the TPB may be fruitfully explored (Conner and Armitage, 1998). Studies suggest that self-identity and personal norms need to be considered alongside TPB components to explain behaviour (Norman and Conner, 1996; Sheeran and Orbell, 2000; Armitage and Conner, 2001). These variables may influence whether cancer patients see themselves as people who normally deal with adversity in a constructive manner, and whether support group use fits with their self-image and perceptions of appropriate ways to deal with illness. Previous use of other types of support groups should also be considered as past behaviour is a strong predictor of future behaviour (Sutton, 2004).

Cancer support groups will not be appropriate for everyone, and ultimately we require a better understanding of when, in what format and for whom they are beneficial. However, the evidence suggests that they on the whole benefit participants, but that very few patients utilise such groups. If low uptake is in part due to misperceptions about support groups, lack of encouragement and surmountable internal and external barriers, these factors need to be addressed to ensure that patients can make informed, supported choices about joining cancer support groups and that groups are easily accessible for those who wish to participate.

\section{ACKNOWLEDGEMENTS}

We wish to thank all respondents to the survey. We are also very grateful to the Cambridge Cancer Help Centre and the East Anglian Cancer Intelligence Unit for all their help with the study. The EORTC QLQ C-30 Quality of Life Group kindly granted permission to use their General Health and Functional Status subscales. The research for this paper was funded by the Directorate of Health and Social Care Midlands and East of England grant RCC11095. The project was approved by the Cambridge Local Research Ethics Committee.

\section{REFERENCES}

Aaronson NK, Ahmedzai S, Bergman B et al. 1993. The European Organisation for Research and Treatment of Cancer QLQ-C30: A quality of life instrument for use in international clinical trials in oncology. $\mathrm{J} \mathrm{Natl}$ Cancer Inst 85: 365-376.

Adamsen L. 2002. 'From victim to agent': The clinical and social significance of self-help group participation for people with life-threatening diseases. Scand $J$ Caring Sci 16: 224-310.

Ajzen I. 1988. Attitudes, Personality and Behaviour. Open University Press: Milton Keynes.

Ajzen I. 2002. Constructing a TPB questionnaire: Conceptual and methodological considerations. www.unix.oit.umass.edu/ aizen/pdf/tpb.measurement.pdf. Summer 2004.

Armitage CJ, Conner M. 2001. Social cognitive determinants of blood donation. J Appl Soc Psychol 31: 1431-1457.

Bauman LJ, Gervey R, Siegel K. 1992. Factors associated with cancer patients' participation in support groups. J Psychosoc Oncol 10: 1-20.

van den Borne HW, Pruyn JFA, van Dam-de May K. 1986. Self-help in cancer patients: A review of studies on the effects of contacts between fellow patients. Patient Educ Couns 8: 367-385.

Cameron LD, Leventhal EA, Leventhal H. 1993. Symptom representations and affect as determinants of care seeking in a community-dwelling, adult sample population. Health Psychol 12: 171-179.

Carver CS. 1997. You want to measure coping but your protocol's too long: Consider the Brief COPE. Int $J$ Behav Med 4: 92-100.

Carver CS, Scheier MF, Weintraub JK. 1989. Assessing coping strategies: A theoretically based approach. $J$ Pers Soc Psychol 56: 267-283.

Cohen S, Wills TA. 1985. Stress, social support and the buffering hypothesis. Psychol Bull 98: 310-357. 
Conner M, Armitage CJ. 1998. Extending the theory of planned behavior: A review and avenues for further research. J Appl Soc Psychol 28: 1429-1464.

Dakof GA, Taylor SE. 1990. Victims' perceptions of social support: What is helpful to whom? J Pers Soc Psychol 58: 80-89.

De Ridder D, Schreurs K. 2001. Developing interventions for chronically ill patients: Is coping a helpful concept? Clin Psychol Rev 21: 205-240.

Eakin EG, Strycker LA. 2001. Awareness and barriers to use of cancer support and information resources by HMO patients with breast, prostate, or colon cancer: Patient and provider perspectives. Psycho-Oncology 10: $103-113$.

Edelman S, Craig A, Kidman AD. 2000. Can psychotherapy increase the survival time of cancer patients? J Psychosom Res 49: 149-156.

Edgar L, Remmer J, Rosberger Z, Rapkin B. 1996. An oncology volunteer support organization: The benefits and fit within the health care system. Psycho-Oncology 5: 331-341.

Fawzy FI, Fawzy NW, Arndt LA, Pasnau RO. 1995. Critical review of psychosocial interventions in cancer care. Arch Gen Psychiat 52: 100-113.

Fayers PM, Aaronson NK, Bjordal K, Groenvold M, Curran D, Bottomley A, on behalf of the EORTC Quality of Life Group. 2001. The EORTC QLQC30 Scoring Manual (3rd edn). European Organisation for Research and Treatment of Cancer: Brussels.

Godin G, Kok G. 1996. The Theory of Planned Behaviour: A review of its applications to healthrelated behaviours. Am J Health Promot 11: 87-98.

Gray R, Fitch M, Davis C, Phillips C. 1997a. A qualitative study of breast cancer self-help groups. Psycho-Oncology 6: 279-289.

Gray RE, Fitch M, Davis C, Phillips C. 1997b. Interviews with men with prostate cancer about their self-help group experience. $J$ Palliative Care 13: 15-21.

Hagger M, Orbell S. 2003. A meta-analytic review of the common-sense model of illness representations. Psychol Health 18: 141-184.

Hardeman W, Johnston M, Johnston DW, Bonetti D, Wareham NJ, Kinmonth AL. 2002. Application of the Theory of Planned Behaviour in behaviour change interventions: A systematic review. Psychol Health 17: 123-158.

Helgeson VS, Cohen S, Schulz R, Yasko J. 1999. Education and peer discussion group interventions and adjustment to breast cancer. Arch Gen Psychiat 56: $340-347$.

Helgeson VS, Cohen S, Schulz R, Yasko J. 2000. Group support interventions for women with breast cancer: Who benefits from what? Health Psychol 19: 107-114.

Hogan BE, Linden W, Najarian B. 2002. Social support interventions. Do they work? Clin Psychol Rev 22: 381-440.
Hosmer DH, Lemeshow S. 2000. Applied Logistic Regression (2nd edn). Wiley Interscience Publication: New York.

Indices of Deprivation. 2000. Regeneration Research Summary Number 31, 2000. Department for Transport, Local Government \& the Regions. http:// www.casa.ucl.ac.uk/2003/imd2000.pdf. Spring 2003.

Katz D, Koppie TM, Wu D et al. 2002. Sociodemographic characteristics and health related quality of life in men attending prostate cancer support groups. J Urology 168: 2092-2096.

Krizek C, Roberts C, Ragan R, Ferrara JJ, Lord B. 1999. Gender and cancer support group participation. Cancer Pract 7: 86-92.

Leventhal H, Benyamini Y, Brownlee S et al. 1997. Illness representations: Theoretical foundations. In Perceptions of Health and Illness, Petrie KJ, Weinman JA (eds). Harwood Academic Publishers: Amsterdam; 19-45.

Leventhal H, Leventhal EA, Cameron L. 2001. Representations, procedures, and affect in illness self-regulation: A perceptual-cognitive model. In Handbook of Health Psychology, Baum A, Revenson TA, Singer JE (eds). Lawrence Erlbaum: Mahwah, New Jersey.

McGovern RJ, Heyman EN, Resnick MI. 2002. An examination of coping style and quality of life of cancer patients who attend a prostate cancer support group. J Psychosoc Oncol 20: 57-68.

Meyer TJ, Mark MM. 1995. Effects of psychosocial interventions with adult cancer patients: A metaanalysis of randomised experiments. Health Psychol 14: 101-108.

Michalec B, van Willigen M, Wilson K, Schreier A, Williams S. 2004. The race gap in support group participation by breast cancer survivors. Real or artefact? Evaluation Rev 28: 123-143.

Moos RH, Shaefer JA. 1986. Life transitions and crises: A conceptual overview. In Coping With Life Crises: An Integrated Approach, Moos RH (ed.). Plenum: New York.

Moss-Morris R, Weinman J, Petrie KJ, Horne R, Cameron LD, Buick D. 2002. The revised illness perception questionnaire (IPQ-R). Psychol Health 17: $1-16$.

Norman P, Conner M. 1996. The role of social cognition models in predicting health behaviours: Future directions. In Predicting Health Behaviour, Conner M, Norman P (eds). Open University Press: Buckingham; 197-225.

Norusis MJ. 1994. SPSS Advanced Statistics 6.1. SPSS Inc: Chicago.

Pascoe S, Edelman S, Kidman A. 2000. Prevalence of psychological distress and use of support services by cancer patients at Sydney hospitals. Aust NZ J Psychiat 34: 785-791.

Pilisuk M, Wentzel P, Barry O, Tennant J. 1997. Participant assessment of a nonmedical breast cancer support group. Altern Ther Health Med 3: 72-80. 
Plass A, Koch U. 2001. Participation of oncological outpatients in psychosocial support. Psycho-Oncology 10: $511-520$.

Poole G, Poon C, Achille M et al. 2001. Social support for patients with prostate cancer: The effect of support groups. J Psychosoc Oncol 19: 1-16.

Sheeran P, Orbell S. 2000. Self-schemas and the theory of planned behaviour. Eur J Soc Psychol 30: 533-550.

Siegel S, Castellan NJ. 1988. Nonparametric Statistics (2nd edn). McGraw-Hill: Singapore.

Stevens MJ, Duttlinger JE. 1998. Correlates of participation in a breast cancer support group. $J$ Psychosom Res 45: 263-275.

Stevenson BS, Coles PM. 1993. A breast cancer support group: Activities and value to mastectomy patients. $J$ Cancer Educ 8: 239-420.

Sutton A. 2004. Determinants of health-related behaviours: Theoretical and methodological issues. In The Sage Handbook of Health Psychology, Sutton S, Baum A, Johnston M (eds). Sage: London.
Taylor SE. 1983. Adjustment to threatening events: A theory of cognitive adaptation. Am Psychol 38: 1161-1173.

Taylor SE, Falke RL, Shoptaw SJ, Lichtman RR. 1986. Social support, support groups and the cancer patient. $J$ Consult Clin Psychol 54: 608-615.

Tennen H, Affleck G, Armeli S, Carney MA. 2000. A daily process approach to coping. Linking theory, research and practice. Am Psychol 55: 626-636.

Thiel de Bocanegra H. 1992. Cancer patients' interest in group support programs. Cancer Nurs 15: 347-520.

Winefield HR, Coventry BJ, Lewis M, Harvey EJ. 2003. Attitudes of patients with breast cancer toward support groups. J Psychosoc Oncol 21: 39-54.

Zigmond AS, Snaith RP. 1983. The hospital anxiety and depression scale. Acta Psychiatr Scand 67: 361-370.

Zimet GD, Dahlem NW, Zimet SG, Farley GK. 1988. The multidimensional scale of perceived social support. J Pers Assess 52: 30-41. 